\title{
Epidemiology and Long-Term Adverse Outcomes in Korean Patients with Congenital Adrenal Hyperplasia: A Nationwide Study
}

\author{
Jung Hee Kim ${ }^{1, *}$, Sunkyu $\mathrm{Choi}^{2}$,*, Young Ah $\mathrm{Lee}^{3}$, Juneyoung $\mathrm{Lee}^{2}$, Sin Gon $\mathrm{Kim}^{4}$ \\ ${ }^{1}$ Department of Internal Medicine, Seoul National University Hospital, Seoul National University College of Medicine; \\ ${ }^{2}$ Department of Biostatistics, Korea University College of Medicine; ${ }^{3}$ Department of Pediatrics, Seoul National University \\ Children's Hospital, Seoul National University College of Medicine; ${ }^{4}$ Division of Endocrinology and Metabolism, Department \\ of Internal Medicine, Korea University College of Medicine, Seoul, Korea
}

Background: Previous studies on the epidemiology and complications of congenital adrenal hyperplasia (CAH) were conducted in Western countries and in children/adolescents. We aimed to explore the epidemiology of $\mathrm{CAH}$, as well as the risk of comorbidities and mortality, in a Korean nationwide case-control study.

Methods: CAH patients $(n=2,840)$ were included between 2002 and 2017 from the National Health Insurance Service database and the Rare Intractable Disease program. CAH patients were compared, at a 1:10 ratio, with age-, sex-, and index year-matched controls $(n=28,400)$.

Results: The point prevalence of CAH patients in Korea was 1 in 18,745 persons in 2017. The annual incidence rate declined between 2003 and 2017 from 3.25 to 0.41 per 100,000 persons. CAH patients were at elevated risk for cardiovascular disease (odds ratio [OR], 1.6; $95 \%$ confidence interval [CI], 1.4 to 1.9 ), stroke (OR, 1.7; 95\% CI, 1.3 to 2.0), diabetes mellitus (OR, 2.8; 95\% CI, 2.6 to 3.1 ), dyslipidemia (OR, 2.4; 95\% CI, 2.2 to 2.6), and psychiatric disorders (OR, 1.5; 95\% CI, 1.3 to 1.6). Fracture risk increased in CAH patients aged over 40 years (OR, 1.4; 95\% CI, 1.1 to 1.7$)$. CAH patients were at higher risk of mortality than controls (hazard ratio, $1.6 ; 95 \% \mathrm{CI}, 1.3$ to 2.0 ).

Conclusion: Our nationwide study showed a recent decline in the incidence of CAH and an elevated risk for cardiovascular, metabolic, skeletal, and psychiatric disorders in $\mathrm{CAH}$ patients. Lifelong management for comorbidity risk is a crucial component of treating $\mathrm{CAH}$ patients.

Keywords: Adrenal hyperplasia, congenital; Epidemiology; Long term adverse effects; Comorbidity; Mortality

\section{INTRODUCTION}

Congenital adrenal hyperplasia $(\mathrm{CAH})$ is a group of genetic dis-

Received: 6 November 2021, Revised: 17 December 2021,

Accepted: 20 December 2021

Corresponding author: Sin Gon Kim

Division of Endocrinology and Metabolism, Department of Internal Medicine, Korea University College of Medicine, 73 Goryeodae-ro, Seongbuk-gu, Seoul 02841 , Korea

Tel: +82-2-920-5890; Fax: +82-2-953-9355, E-mail: k50367@korea.ac.kr orders characterized by deficiencies in several enzymes involved in adrenal steroidogenesis. The most common type is a 21-hydroxylase deficiency, which results in glucocorticoid and/

\section{Copyright $\odot 2022$ Korean Endocrine Society}

This is an Open Access article distributed under the terms of the Creative Commons Attribution Non-Commercial License (https://creativecommons.org/ licenses/by-nc/4.0/) which permits unrestricted non-commercial use, distribution, and reproduction in any medium, provided the original work is properly cited.

*These authors contributed equally to this work. 
or mineralocorticoid deficiency, and androgen excess. The extent of enzyme deficiency varies from classic (salt-wasting or simple virilizing) to nonclassic types [1]. The worldwide incidence of classic CAH ranges from 1:10,000 to 1:20,000 live births $[1,2]$. In Asia, similar incidence rates have been reported [3-5]. However, complete national data on the incidence of $\mathrm{CAH}$ has not been published yet.

Glucocorticoid and/or mineralocorticoid replacement is a cornerstone of the treatment of CAH patients with 21-hydroxylase deficiency. Two therapeutic goals should be fulfilled in the most common type of CAH caused by 21-hydroxylase deficiency: to substitute deficient hormones and to suppress adrenocorticotropic hormone-driven androgen excess. However, supraphysiologic and nocturnal glucocorticoid regimens are needed to reduce androgen excess. Therefore, current therapies are still accompanied by metabolic and cardiovascular comorbidities throughout the patients' lifetime, even though most CAH patients survive beyond childhood thanks to the introduction of glucocorticoid treatment and prenatal/neonatal diagnosis.

Previous studies on adverse outcomes in CAH patients were conducted in Western countries [6-11]. A recent meta-analysis revealed that $\mathrm{CAH}$ patients had high blood pressure, carotid intimal thickness, and insulin resistance, but similar fasting plasma glucose and serum lipid levels to healthy controls [12]. However, these studies harbored moderate to high risks of bias and were single- or multi-center studies. Although a national study on cardiovascular risk and mortality in CAH patients was reported in Sweden [10,13], there have been no studies in Asia on national epidemiology, long-term complications, and mortality in CAH patients.

Due to the small number of CAH patients, single or multicenter studies are insufficient to clarify the long-term adverse outcomes of CAH patients. Moreover, it is not easy to conduct prospective longitudinal studies since it takes decades to elucidate the occurrence of comorbidities. In South Korea, a national database called the National Health Insurance Service (NHIS) can be used to investigate the epidemiology and long-term complications of rare diseases. The NHIS database includes healthrelated information from the whole population in South Korea from 2002 to 2019.

Here, we aimed to explore the epidemiology of CAH in South Korea and the risk of long-term adverse health outcomes and mortality compared to the general population-based on the nationwide population-based database.

\section{METHODS}

\section{Ethical considerations}

The Institutional Review Board of Seoul National University Hospital approved the study protocol (IRB No. 2004-068-1116). The need for informed consent was waived due to the deidentification of personal information in the NHIS.

\section{Data source}

We conducted a nationwide population-based study using the NHIS database. The Korean National Health Insurance Program covers approximately $97.2 \%$ of the Korean population. Therefore, all healthcare service data for reimbursements are stored in the NHIS database. The data included demographics, diagnostic codes defined by the 10th version of the International Classification of Diseases (ICD-10), prescriptions, and diagnostic or surgical procedures. In addition, the Korean government initiated the Rare Intractable Disease (RID) program for CAH in 2004 , which reduces co-payments by $10 \%$ for rare intractable diseases to relieve the economic burden of patients within the NHIS. Therefore, data on medical information of all CAH patients are stored in the NHIS or RID database.

In this study, patients with CAH were defined as those who (1) utilized healthcare services twice or more with the ICD-10 diagnostic codes for $\mathrm{CAH}$ (V115, E25/E25.0/E25.8/E25.9) as a primary or secondary diagnosis from 2002 to 2017, and (2) were prescribed a glucocorticoid (hydrocortisone, prednisolone, or dexamethasone) or fludrocortisone for more than 6 months. We included only cases that met all the above-mentioned diagnostic criteria. Since the RID program had been started as a pilot program before 2009, we included cases with two or more instances of the ICD-10 diagnostic codes for CAH (E25/E25.0/ E25.8/E25.9) listed as a primary or secondary diagnosis before 2009. However, after 2009, we included cases with one or more instance of the RID code V115 and one or more instance of the ICD-10 diagnostic codes for CAH (E25/E25.0/E25.8/E25.9) as a primary or secondary diagnosis.

To analyze the risk of comorbidities, we set up a control group to represent the general population. We randomly selected subjects who had undergone appendectomy without a diagnosis of $\mathrm{CAH}$ during the same period as the control group. Ten age-, sex-, and index year-matched controls per $\mathrm{CAH}$ patient were selected $(n=28,400)$.

The point prevalence of CAH in 2017 was presented. Incident cases of CAH were reported between 2003 and 2017, since CAH patients with a diagnostic code in 2002 might have been 
diagnosed before 2002. Regarding the incidence of newborns/ infants, we included CAH patients diagnosed from 2002 to 2017. Neonatal screening for CAH began in 2006 in Korea. The treatment regimen, including glucocorticoids and fludrocortisone, was retrieved from the prescription data from the last 1 year before the last visit.

\section{Assessment of comorbidities}

Comorbidities were defined as present based on the presence of the following diagnostic codes for at least two principal or secondary diagnoses. The incidence of comorbidities from 2002 to 2019 was incorporated into our study. The comorbidities examined were coronary artery disease (I20-I25); stroke, including both ischemic stroke (I63, I64, I693, I694, G45) and hemorrhagic stroke (I60-I62, I690, I692); thromboembolism (I26, I80, I82); diabetes mellitus (E11, E12, E13, E14); dyslipidemia (E78); hypertension (I10-I13, I15); fracture (M843, M844, S12, S22, S32, S42, S52, S62, S72, S82, S92, T02); infectious diseases such as enteral infections (A00-A09), tuberculosis (A15A19), and other bacterial infections (A20-A28, A30-A49, A50A64); and psychiatric disorders, including depressive disorder (F32, F33, F34) and psychotic disorder (F20-F29). The mortality rates among the $\mathrm{CAH}$ patients and the controls were observed from the index date to December 2019 using the national death statistics.

\section{Statistical analysis}

The patients' numbers of events are presented as numbers (\%). The control group was chosen by propensity score matching of age, sex, and index year with the $\mathrm{CAH}$ group. Patients were matched 1:10 according to their propensity scores using the nearest neighbor approach (maximum caliper distance, 0.1 ). We performed univariable logistic regression analyses for the risk of comorbidities to estimate odds ratios (ORs) and 95\% confidence intervals (CIs). Subgroup analyses were performed by age and sex. The overall survival probability for each group was estimated using Kaplan-Meier analysis, and the log-rank test was used to compare probabilities between groups. Given that $\mathrm{CAH}$ patients have been exposed to the disease since they were born, patients' age was considered the disease duration. Cox proportional-hazard models were performed to estimate hazard ratios (HRs) and 95\% CIs. All statistical analyses were performed using SAS version 9.4 (SAS Institute Inc., Cary, NC, USA) with two-sided tests, and the statistical significance level was set at 0.05 .

\section{RESULTS}

\section{Epidemiology of CAH}

The overall number of CAH patients in South Korea from 2002 to 2017 was 2,840 . There was no difference according to sex (50.5\% male). As of 2017, there were 2,733 surviving patients, and the Korean population was 51,230,704. Thus, the point prevalence of CAH adults in Korea was 1 in 18,745 persons. In $2017,35.2 \%(n=999)$ of all CAH patients were over 20 years of age (Table 1).

To assess the incidence of $\mathrm{CAH}$, we excluded $\mathrm{CAH}$ patients who had diagnostic codes in $2002(n=1,239)$, since they may have been diagnosed before 2002. From 2003 to 2017, there were 1,601 newly diagnosed $\mathrm{CAH}$ patients. The average annual incidence rate was 2.16 per 100,000 and declined from 3.25 per 100,000 persons in 2003 to 0.41 in 2017 (Fig. 1).

As shown in Fig. 2, we further analyzed the incidence of $\mathrm{CAH}$ in newborns and infants. Since neonatal screening tests for CAH were launched in 2006, the proportion of neonates/infants among newly diagnosed $\mathrm{CAH}$ patients increased from $72 \%$ to $96 \%$ (Table 2). The average incidence of $\mathrm{CAH}$ was 1 per 4,984 live births, ranging from 1 per 3,164 live births in 2007 to 1 per 17,889 live births in 2017.

\section{Treatment regimen}

We investigated the treatment regimen for 6 months or more within the 1 year before the last visit (Fig. 3). A glucocorticoid was prescribed for most CAH patients $(98.7 \%, n=2,800)$. Among glucocorticoid users, the proportion of those with prescriptions for hydrocortisone, prednisolone/methylprednisolone, dexamethasone, and combinations thereof was $26.4 \%(n=738)$, $68.4 \%(n=1,914), 3.8 \%(n=42)$, and $1.5 \%(n=42)$, respective-

Table 1. Age Distribution of Congenital Adrenal Hyperplasia Patients in 2017 in Korea

\begin{tabular}{lrcc}
\hline Age, yr & Male & Female & Total no. (\%) \\
\hline Number & 1,434 & 1,406 & $2,840(100.0)$ \\
$0-5$ & 195 & 166 & $361(12.7)$ \\
$6-9$ & 322 & 240 & $562(19.8)$ \\
$10-19$ & 490 & 428 & $918(32.3)$ \\
$20-29$ & 152 & 200 & $352(12.4)$ \\
$30-39$ & 67 & 124 & $191(6.7)$ \\
$40-49$ & 38 & 77 & $115(4.0)$ \\
$50-59$ & 51 & 46 & $97(3.4)$ \\
$\geq 60$ & 119 & 125 & $244(8.6)$ \\
\hline
\end{tabular}


ly. Fludrocortisone only, or in combination with glucocorticoid, was prescribed in $22.4 \%$ of all patients $(n=636)$.

\section{Comorbidity risks in CAH patients}

We performed logistic regression analysis for the risk of several comorbidities in $\mathrm{CAH}$ patients compared with age- and sex- matched controls. The risk of cardiovascular disease and stroke was higher in $\mathrm{CAH}$ patients than in the control group (OR, 1.6 [95\% CI, 1.4 to 1.9]; and OR, 1.7 [95\% CI, 1.3 to 2.0], respectively). The risk of thromboembolism was similar between the two groups. CAH patients harbored a 2- to 3-fold higher risk for diabetes mellitus, dyslipidemia, and hypertension than controls

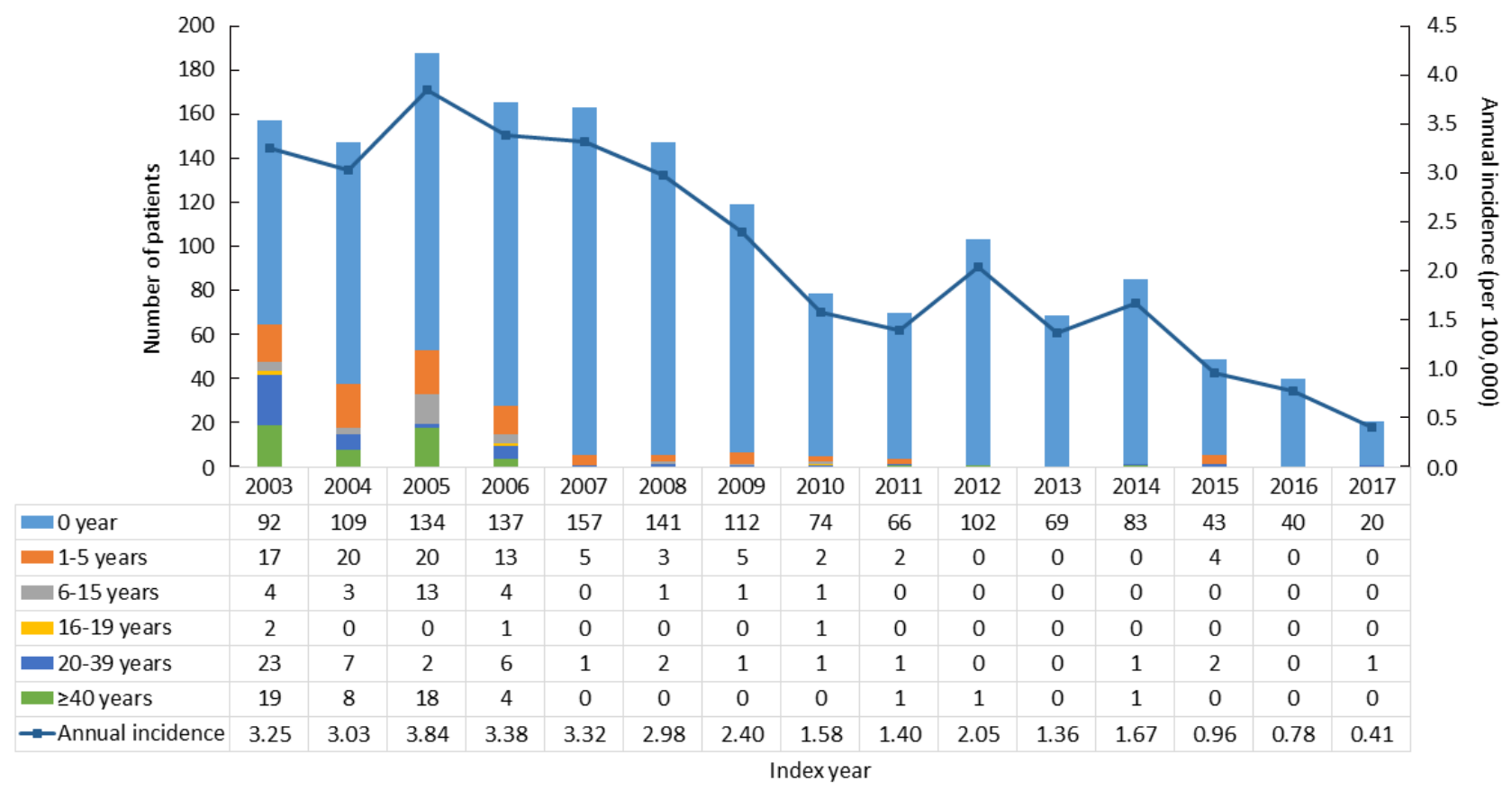

Fig. 1. Annual incidence and number of patients with congenital adrenal hyperplasia according to age and the index year (2003 to 2017).

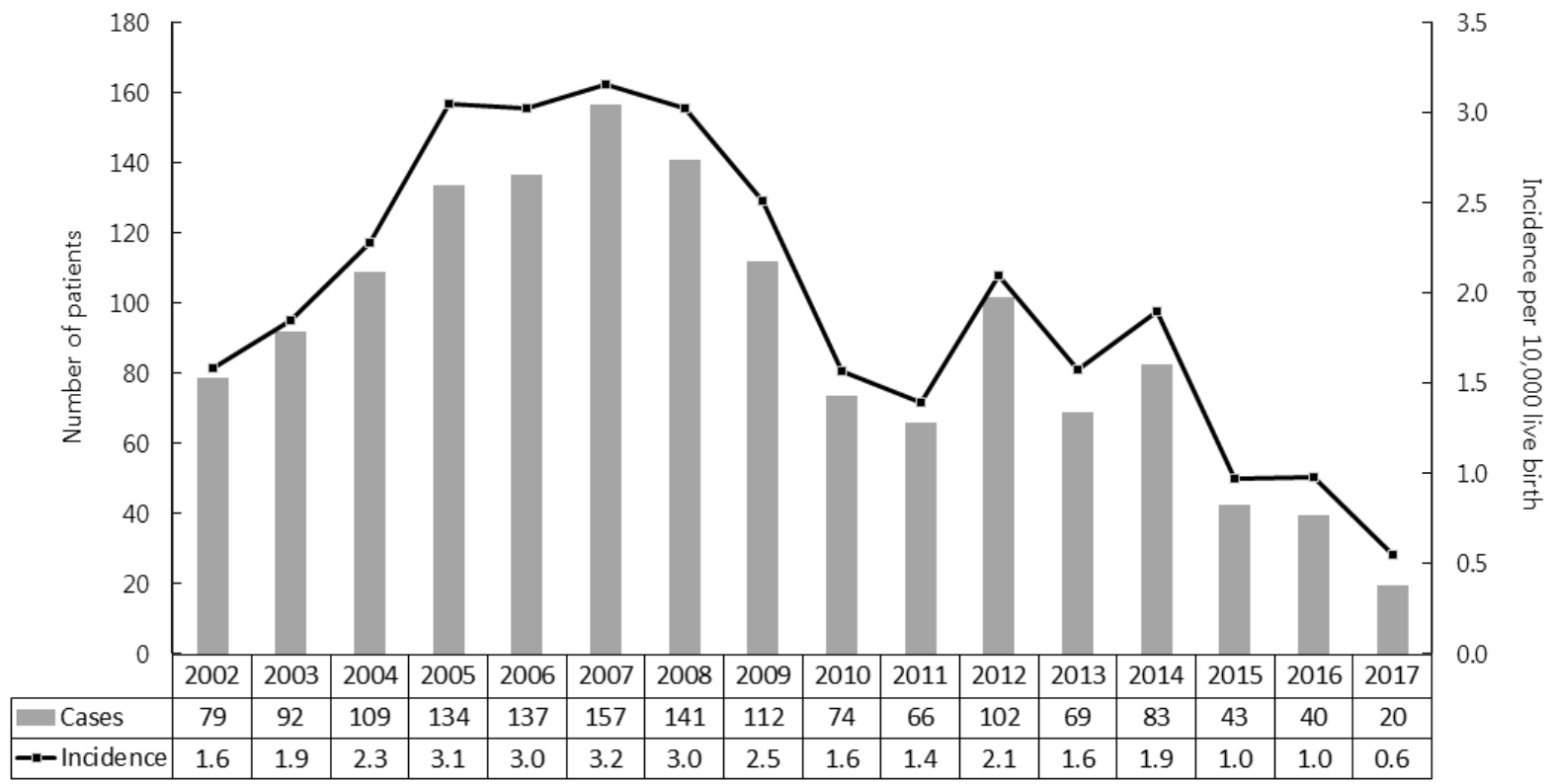

Fig. 2. Annual incidence per 10,000 live births and number of newborns/infants with congenital adrenal hyperplasia according to the index year (2002 to 2017). 
(OR, 2.8 [95\% CI, 2.6 to 3.1]; OR, 2.4 [95\% CI, 2.2 to 2.6]; and OR, 2.9 [95\% CI, 2.6 to 3.2], respectively). However, the overall risk of fractures and infections was not different between the $\mathrm{CAH}$ patients and the control group. The CAH patients had a 1.5-fold higher risk for psychiatric disorders than the controls (95\% CI, 1.3 to 1.6 ) (Table 3 ).

We performed a subgroup analysis according to age and sex (Table 4). In CAH patients aged below 40 years, the risk of diabetes mellitus, dyslipidemia, and hypertension was higher than that in controls, while the prevalence of other comorbidities was not significantly different. The comorbidity risk in $\mathrm{CAH}$ patients aged over 40 years was similar to that in all CAH patients. However, the fracture risk increased in $\mathrm{CAH}$ patients aged over 40 years (OR, 1.4; 95\% CI, 1.1 to 1.7$)$. In addition, in this age group, female $\mathrm{CAH}$ patients, but not males, had a higher risk for thromboembolism (OR, 1.7; 95\% CI, 1.2 to 2.7 ).

Table 2. Proportion of Newborns and Infants among Congenital Adrenal Hyperplasia Patients before and after the Introduction of Neonatal Screening in Korea

\begin{tabular}{lccc}
\hline Age, yr & $2003-2017$ & $2003-2006$ & $2007-2017$ \\
\hline 0 & $1,379(86.1)$ & $472(72.0)$ & $907(96.0)$ \\
$1-5$ & $91(5.7)$ & $70(10.7)$ & $21(2.2)$ \\
$6-15$ & $27(1.7)$ & $24(3.7)$ & $3(0.3)$ \\
$16-19$ & $4(0.2)$ & $3(0.5)$ & $1(0.1)$ \\
$20-39$ & $48(3.0)$ & $38(5.8)$ & $10(1.1)$ \\
$\geq 40$ & $52(3.2)$ & $49(7.5)$ & $3(0.3)$ \\
Total & $1,601(100.0)$ & $656(100.0)$ & $945(100.0)$ \\
\hline
\end{tabular}

Values are expressed as number (\%).

\section{Mortality risk}

Next, we assessed whether the mortality risk was higher in CAH patients than in the control group (Table 5). Due to the nature of the NHIS data, all CAH patients and controls were followed up. Since CAH is a hereditary disease, we assumed the
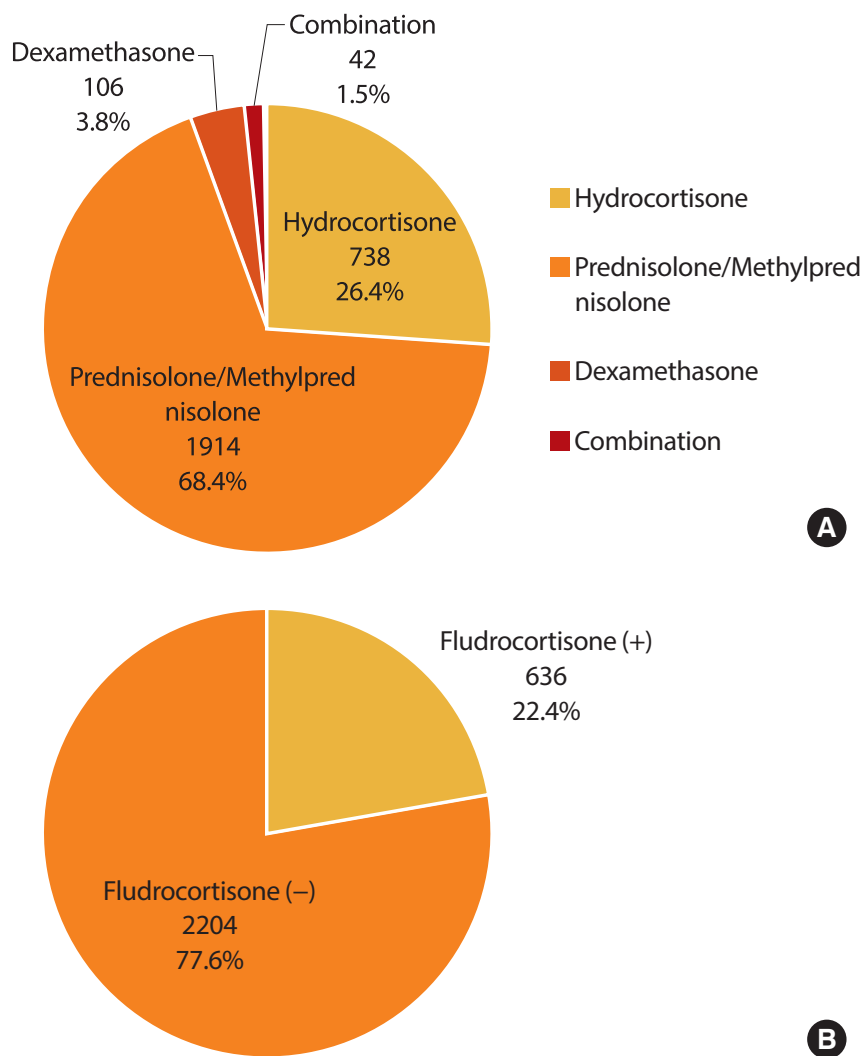

B

Fig. 3. (A) Glucocorticoid and (B) mineralocorticoid regimens with 6 months or more duration within 1 year before the last visit.

Table 3. Comorbidity Risk in Congenital Adrenal Hyperplasia Patients $(n=2,840)$, Compared with Age- and Sex-Matched Controls $(n=28,400)$

\begin{tabular}{lcccc}
\hline Variable & CAH $(n=2,840)$ & Control $(n=28,400)$ & OR $(95 \%$ CI $)$ & $P$ value \\
\hline Cardiovascular disease & $209(7.4)$ & $1,314(4.6)$ & $1.6(1.4-1.9)$ & $<0.001$ \\
Stroke & $133(4.7)$ & $818(2.9)$ & $1.7(1.3-2.0)$ & $<0.001$ \\
Diabetes mellitus & $569(20.0)$ & $2,311(8.1)$ & $2.8(2.6-3.1)$ & $<0.001$ \\
Dyslipidemia & $941(33.1)$ & $4,924(17.3)$ & $2.4(2.2-2.6)$ & $<0.001$ \\
Hypertension & $630(22.2)$ & $2,566(9.0)$ & $2.9(2.6-3.2)$ & $<0.001$ \\
Thromboembolism & $32(1.1)$ & $223(0.8)$ & $1.4(1.0-2.1)$ & 0.055 \\
Fracture & $757(26.7)$ & $7,348(25.9)$ & $1.0(1.0-1.1)$ & 0.361 \\
Infection & $2,455(86.4)$ & $24,837(87.5)$ & $0.9(0.8-1.0)$ & 0.122 \\
Psychiatric disorder & $445(15.7)$ & $3,143(11.1)$ & $1.5(1.3-1.6)$ & $<0.001$
\end{tabular}

Values are expressed as number $(\%)$.

$\mathrm{CAH}$, congenital adrenal hyperplasia; $\mathrm{OR}$, odds ratio; $\mathrm{CI}$, confidence interval. 
Table 4. Comorbidity Risk in Congenital Adrenal Hyperplasia Patients Compared with Age- and Sex-Matched Controls According to Age and Sex

\begin{tabular}{|c|c|c|c|c|c|c|c|c|c|}
\hline \multirow{2}{*}{ Comorbidity } & \multicolumn{3}{|c|}{$0-19$ years old } & \multicolumn{3}{|c|}{ 20-39 years old } & \multicolumn{3}{|c|}{$\geq 40$ years old } \\
\hline & All & Females & Males & All & Females & Males & All & Females & Males \\
\hline Number & 1,796 & 811 & 985 & 569 & 332 & 237 & 475 & 263 & 212 \\
\hline Cardiovascular disease & $\begin{array}{c}1.8 \\
(0.8-4.0)\end{array}$ & $\begin{array}{c}0.9 \\
(0.2-3.8)\end{array}$ & $\begin{array}{c}3 \\
(1.1-8.1)\end{array}$ & $\begin{array}{c}1.6 \\
(0.9-2.8)\end{array}$ & $\begin{array}{c}1.4 \\
(0.7-3.1)\end{array}$ & $\begin{array}{c}1.9 \\
(0.8-4.3)\end{array}$ & $\begin{array}{c}2.1 \\
(1.7-2.6)\end{array}$ & $\begin{array}{c}2.3 \\
(1.8-3.0)\end{array}$ & $\begin{array}{c}1.9 \\
(1.4-2.5)\end{array}$ \\
\hline Stroke & $\begin{array}{c}0.9 \\
(0.8-1.0)\end{array}$ & $\begin{array}{c}4.1 \\
(1.6-10.6)\end{array}$ & $\begin{array}{c}0.9 \\
(0.2-3.7)\end{array}$ & $\begin{array}{c}2.1 \\
(0.8-5.4)\end{array}$ & $\begin{array}{c}2.2 \\
(0.7-6.6)\end{array}$ & $\begin{array}{c}1.6 \\
(0.2-13.1)\end{array}$ & $\begin{array}{c}1.9 \\
(1.5-2.4)\end{array}$ & $\begin{array}{c}2.3 \\
(1.7-3.2)\end{array}$ & $\begin{array}{c}1.5 \\
(1.1-2.1)\end{array}$ \\
\hline Diabetes mellitus & $\begin{array}{c}7.3 \\
(5.8-9.2)\end{array}$ & $\begin{array}{c}8.4 \\
(6.1-11.6)\end{array}$ & $\begin{array}{c}6.4 \\
(4.6-8.9)\end{array}$ & $\begin{array}{c}8.5 \\
(6.7-10.7)\end{array}$ & $\begin{array}{c}7.9 \\
(5.9-10.7)\end{array}$ & $\begin{array}{c}9.4 \\
(6.5-13.7)\end{array}$ & $\begin{array}{c}2.6 \\
(2.1-3.1)\end{array}$ & $\begin{array}{c}2.4 \\
(1.9-3.2)\end{array}$ & $\begin{array}{c}2.7 \\
(2.0-3.7)\end{array}$ \\
\hline Dyslipidemia & $\begin{array}{c}3.6 \\
(3.1-4.2)\end{array}$ & $\begin{array}{c}3.9 \\
(3.2-4.8)\end{array}$ & $\begin{array}{c}3.4 \\
(2.7-4.2)\end{array}$ & $\begin{array}{c}4.4 \\
(3.7-5.3)\end{array}$ & $\begin{array}{c}3.9 \\
(3.1-5.0)\end{array}$ & $\begin{array}{c}5.2 \\
(4.0-6.9)\end{array}$ & $\begin{array}{c}3.1 \\
(2.4-4.0)\end{array}$ & $\begin{array}{c}3 \\
(2.1-4.2)\end{array}$ & $\begin{array}{c}3.2 \\
(2.2-4.8)\end{array}$ \\
\hline Hypertension & $\begin{array}{c}18.5 \\
(13.8-24.8)\end{array}$ & $\begin{array}{c}27.6 \\
(17.9-42.5)\end{array}$ & $\begin{array}{c}12.6 \\
(8.4-18.9)\end{array}$ & $\begin{array}{c}18 \\
(14.2-22.7)\end{array}$ & $\begin{array}{c}17.8 \\
(13.0-24.3)\end{array}$ & $\begin{array}{c}18.5 \\
(13.0-26.2)\end{array}$ & $\begin{array}{c}1.9 \\
(1.6-2.3)\end{array}$ & $\begin{array}{c}2.1 \\
(1.6-2.7)\end{array}$ & $\begin{array}{c}1.7 \\
(1.3-2.3)\end{array}$ \\
\hline Thromboembolism & $\begin{array}{c}1.34 \\
(0.4-4.4)\end{array}$ & NA & $\begin{array}{c}2.7 \\
(0.8-9.9)\end{array}$ & $\begin{array}{c}0.6 \\
(0.1-2.4)\end{array}$ & $\begin{array}{c}1 \\
(0.2-4.5)\end{array}$ & NA & $\begin{array}{c}1.7 \\
(1.2-2.7)\end{array}$ & $\begin{array}{c}2.3 \\
(1.3-3.9)\end{array}$ & $\begin{array}{c}1.3 \\
(0.7-2.5)\end{array}$ \\
\hline Fracture & $\begin{array}{c}0.9 \\
(0.8-1.0)\end{array}$ & $\begin{array}{c}0.8 \\
(0.7-1.0)\end{array}$ & $\begin{array}{c}1 \\
(0.9-1.1)\end{array}$ & $\begin{array}{c}1.2 \\
(0.9-1.4)\end{array}$ & $\begin{array}{c}1.2 \\
(0.9-1.6)\end{array}$ & $\begin{array}{c}1.2 \\
(0.9-1.5)\end{array}$ & $\begin{array}{c}1.4 \\
(1.1-1.7)\end{array}$ & $\begin{array}{c}1.4 \\
(1.0-1.8)\end{array}$ & $\begin{array}{c}1.4 \\
(1.0-1.9)\end{array}$ \\
\hline Infection & $\begin{array}{c}0.8 \\
(0.6-1.0)\end{array}$ & $\begin{array}{c}0.7 \\
(0.5-1.0)\end{array}$ & $\begin{array}{c}0.9 \\
(0.6-1.3)\end{array}$ & $\begin{array}{c}0.8 \\
(0.7-0.9)\end{array}$ & $\begin{array}{c}0.6 \\
(0.5-0.8)\end{array}$ & $\begin{array}{c}1.1 \\
(0.8-1.5)\end{array}$ & $\begin{array}{c}1.1 \\
(0.9-1.4)\end{array}$ & $\begin{array}{c}1.3 \\
(1.0-1.7)\end{array}$ & $\begin{array}{c}1 \\
(0.8-1.3)\end{array}$ \\
\hline Psychiatric disorder & $\begin{array}{c}1.6 \\
(1.2-2.0)\end{array}$ & $\begin{array}{c}1.4 \\
(1.0-2.0)\end{array}$ & $\begin{array}{c}1.7 \\
(1.2-2.4)\end{array}$ & $\begin{array}{c}1.2 \\
(1.0-1.5)\end{array}$ & $\begin{array}{c}0.8 \\
(0.6-1.1)\end{array}$ & $\begin{array}{c}2.2 \\
(1.6-3.0)\end{array}$ & $\begin{array}{c}2.3 \\
(1.9-2.7)\end{array}$ & $\begin{array}{c}2 \\
(1.6-2.6)\end{array}$ & $\begin{array}{c}2.7 \\
(2.0-3.5)\end{array}$ \\
\hline
\end{tabular}

Values are expressed as odds ratio ( $95 \%$ confidence interval).

NA, not available.

Table 5. Mortality in Congenital Adrenal Hyperplasia Patients Compared with Age- and Sex-Matched Controls

\begin{tabular}{lccc}
\hline Death & CAH & $\begin{array}{c}\mathrm{HR} \\
(95 \% \mathrm{CI})\end{array}$ & $P$ value \\
\hline $\begin{array}{l}\text { Whole population } \\
(n=2,840)\end{array}$ & $107(3.8)$ & $1.6(1.3-2.0)$ & $<0.001$ \\
$\begin{array}{l}\text { Year of birth } 2003-2017 \\
(n=1,451)\end{array}$ & $10(0.7)$ & $3.3(1.6-6.7)$ & $<0.001$ \\
\hline
\end{tabular}

Values are expressed as number (\%).

$\mathrm{CAH}$, congenital adrenal hyperplasia; HR, hazard ratio; CI, confidence interval.

disease duration as equivalent to patient age. Among study subjects, 107 of the 2,840 CAH patients and 580 of the 28,400 control group died. CAH patients were at higher risk for death controls (HR, 1.6; 95\% CI, 1.3 to 2.0; $P$ value for log-rank test $<0.001$ ) (Fig. 4). We further performed a survival analysis in patients born since 2003. Among 1,451 CAH patients and 14,998 controls, 10 and 33 died, respectively. The HR for mortality in this age group was higher than that in all age groups (3.3; $95 \%$ CI, 1.6 to 6.7 ; $P$ value for log-rank test $<0.001)$.

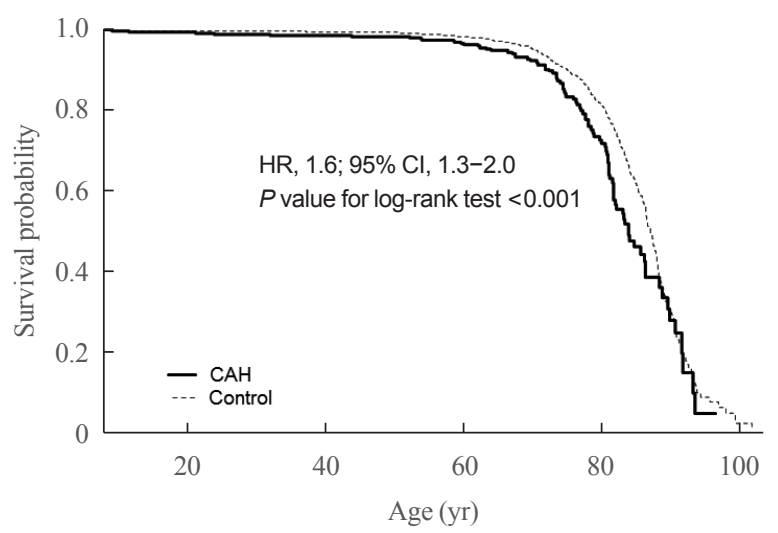

Fig. 4. Survival probability of congenital adrenal hyperplasia (CAH) patients compared with age- and sex-matched controls. HR, hazard ratio; $\mathrm{CI}$, confidence interval.

\section{DISCUSSION}

The present Korean nationwide study reported that the point prevalence of CAH in 2017 was 1 per 18,745 persons. The average annual incidence was 2.16 per 100,000 persons and 1 per 4,984 live births in Korea. The most common prescribed gluco- 
corticoid regimen in $\mathrm{CAH}$ patients was prednisolone/methylprednisolone $(68.4 \%)$. The comorbidity risks for fracture, cardiovascular, metabolic, and psychiatric disorders were increased in $\mathrm{CAH}$ patients compared with age- and sex-matched controls. Moreover, $\mathrm{CAH}$ patients were at higher mortality risk than controls.

The incidence of CAH has mainly been reported in Western countries [1]. This is the first nationwide data in Asia, although there have been regional data or meta-analyses in Asian populations. The incidence of $\mathrm{CAH}$ in China was 1 per 6,084 live births in an early study with a relatively small sample size $(n=30,000)$ [14], and 1 per 23,024 live births in a recent metaanalysis of newborn screening results [5]. In Japan, data from Sapporo and Tokyo revealed incidence rates of 1 per 19,160 and 1 per 19,860 live births, respectively [3,4]. We are the first to report the nationwide incidence of $\mathrm{CAH}$ patients in Asia. When we investigated the nationwide trends in the incidence of $\mathrm{CAH}$ in South Korea, the incidence declined from 1 per 3,000-6,000 live births before 2014 to 1 per 10,000-17,000 live births after 2014. A similar phenomenon was also found in a Swedish registry [15]. Early diagnosis by neonatal screening test may eliminate the time lag before these patients contribute to the incidence, leading to an increasing incidence shortly after 2006 followed by a gradual decrease in incidence thereafter. Nonetheless, the reason why the incidence of $\mathrm{CAH}$ declined in recent years remains unclear. The decreasing marriage or birth rate in Korean adults and advanced genetic counseling could be possibilities, but the exact explanation remains to be determined.

Current glucocorticoid regimens in $\mathrm{CAH}$ patients cannot mimic the normal physiological cortisol rhythm. The main goals of treatment are different in children and adults. The aim of treatment of $\mathrm{CAH}$ in growing children is to prevent adrenal crises and attain normal growth and puberty, while the focus in adulthood is to preserve fertility and avoid long-term complications. Although the guideline recommends hydrocortisone in growing children, no consensus on the optimal glucocorticoid regimen exists for managing adult $\mathrm{CAH}$ patients [1]. In a systematic review, hydrocortisone and prednisolone had similar efficacy and safety, while dexamethasone was more effective in suppressing androgen excess but was related to obesity and reduced bone mineral density (BMD) [16]. In a French study, 94 (90.4\%) of 104 adults, were treated with hydrocortisone [17], whereas hydrocortisone (26\%), prednisolone (43\%), and dexamethasone (19\%) were prescribed in 203 adults from the United Kingdom Congenital Adrenal Hyperplasia Adult Study Executive [6]. Han et al. [18] recommended that dexamethasone should be avoided due to the risk of insulin resistance. In our study, the most common glucocorticoid regimen in 2017 was prednisolone/methylprednisolone (68.4\%), and dexamethasone was used only in $3.8 \%$ of patients.

Few studies have compared metabolic and cardiovascular risks in $\mathrm{CAH}$ patients with controls. We showed that $\mathrm{CAH}$ patients aged over 40 years harbored a higher risk for cardiovascular disease and stroke than the control group. A Swedish study showed that the risks for diabetes, hypertension, and hyperlipidemia were higher in $\mathrm{CAH}$ patients aged over 40 years, which agrees with the present study [10]. However, the risk for acute coronary syndrome and stroke was not different between the $\mathrm{CAH}$ and control groups in the Swedish study [10]. Furthermore, other studies have reported similar risks for diabetes mellitus, hypertension, and dyslipidemia between $\mathrm{CAH}$ and control groups $[6,12,19]$. This difference may have resulted from the younger ages of the patient cohorts in other studies since cardiovascular disease occurs more frequently at an older age, and our study included the largest number of CAH patients aged over 40 years $(n=475)$. A recent meta-analysis supports our explanation, since $\mathrm{CAH}$ patients showed higher insulin resistance, but similar glucose and lipid levels compared with controls [12]. Thus, it takes time to develop diabetes mellitus or dyslipidemia from insulin resistance. Additionally, differences in glucocorticoid and mineralocorticoid doses, treatment target goals, disease control status, and 21-hydroxylase activity may contribute to the discrepant results. Glucocorticoid overtreatment or longterm use may contribute to higher metabolic risk in CAH $[6,20]$. However, poor disease control with androgen excess can be related to insulin resistance in women [7,21-25]. Unfortunately, we did not have biochemical data and could not elucidate whether metabolic risk resulted from overtreatment or undertreatment. Moreover, the presence of obesity, a strong risk factor for cardiovascular diseases, could not be assessed due to the unavailability of height and weight data in the NHIS database.

Venous thromboembolism risk was higher in the Swedish cohort, whereas in our cohort, the risk was marginal. Although glucocorticoid use is related to hypercoagulopathy, the risk of thromboembolism in Asia is lower than in Western countries [26]. Differences in ethnicity, age, and the definition of diseases may explain the discrepancy.

The fracture risk was also high in $\mathrm{CAH}$ patients aged over 40 years, whereas it was similar in those aged below 40 years. This may imply a high osteoporotic fracture risk in $\mathrm{CAH}$ patients. Women with $\mathrm{CAH}$ had lower BMD and higher osteoporotic fracture risk than controls [27]. The use of prednisolone rather 
than hydrocortisone and higher glucocorticoid doses may be related to low BMD [28]. However, Auer et al. [29] reported sexdimorphic effects of adrenal androgen on bone. In men with $\mathrm{CAH}$, adrenal androgen excess suppresses testicular androgen, resulting in detrimental effects on bone health. In women with $\mathrm{CAH}$, adrenal androgen excess may benefit bone health if regular menstruation is maintained, indicating that peripheral aromatization of adrenal androgen may be sufficient to maintain bone health [29]. Since no sex difference in fracture risk was found in our study, hypogonadism in men and glucocorticoid overdose in women might contribute to fracture risk.

In addition, we identified a higher risk for psychiatric disorders, including mood or psychotic disorders, in CAH patients. The Swedish group also identified an increased risk for any psychiatric risk in men and women with CAH before the introduction of neonatal screening [30,31]. They assumed that the delayed initiation of glucocorticoid therapy with prolonged exposure to high androgen levels might have contributed to the increased rate of psychiatric disorders. However, the disease itself or the long-term exposure to supraphysiologic glucocorticoids may affect the occurrence of depression and substance misuse. In future studies, quality of life or psychiatric disorders should be considered.

To the best of our knowledge, there have been only two studies on mortality rates in adults with CAH. In the Sweden national population-based registry, the HR was 2.3 and 3.5 in men and women with $\mathrm{CAH}$, respectively [13]. In the UK Clinical Practice Research Datalink, the $270 \mathrm{CAH}$ patients identified were at a 5-fold higher risk than controls, with an age of death 18 years earlier than controls [32]. As the first such study in Asia, we presented a higher mortality risk in adults with $\mathrm{CAH}$ to a lesser degree than reported in other countries. Although we did not assess the cause of death in our study subjects, the most common causes of death in the Swedish study were adrenal crisis $(42 \%)$ and cardiovascular disease (32\%) [13]. Early diagnoses through the neonatal screening testing program implemented in Korea have likely prevented fatal adrenal crises (e.g., in boys with salt-wasting $\mathrm{CAH}$ ). Thus, now is the time to improve the long-term survival in CAH adults.

Several limitations were inevitable in the present study. We could not assess the genotype-phenotype correlation and differentiate specific CAH types based on the enzyme deficiency due to the inaccessibility of genetic or biochemical data in the NHIS database. In addition, we only utilized operational definition of $\mathrm{CAH}$ based on diagnostic codes and prescriptions. Nevertheless, the accuracy of the diagnoses can be ensured due to the
Korean RID program. Since the NHIS did not provide detailed information on prescriptions, we identified the presence of diabetes mellitus, dyslipidemia, and hypertension based on the diagnostic codes. Therefore, the prevalence of these diseases may be overestimated. Nonetheless, we compared the comorbidity risk of $\mathrm{CAH}$ patients with age- and sex-matched controls at a 1:10 ratio. Since the intrinsic nature of the NHIS database depends on retrieved hospital claims data, patients who truly had a disease but did not visit the hospital can be categorized as not having the disease. In addition, ascertainment bias should be addressed since $\mathrm{CAH}$ patients had more chances to be diagnosed with comorbidities than controls. However, severe cases may be detected equally in $\mathrm{CAH}$ patients and controls. We assessed the mortality risk, but the cause of death was not accessible due to NHIS policies.

Despite the above-mentioned limitations, a strength of this study is that it is the first nationwide population-based study in Asian $\mathrm{CAH}$ patients of all ages. To our knowledge, there has been only one nationwide population-based study that assessed the metabolic and cardiovascular risks of CAH [10]. Secondly, the nationwide time trend of epidemiology in $\mathrm{CAH}$ patients could be assessed without loss to follow-up. Thirdly, we also included the largest number of $\mathrm{CAH}$ patients to date in a study assessing the risk of comorbidities and mortality, comparing them with 1:10 age- and sex-matched controls.

In conclusion, our nationwide population-based study identified a recent decline in the incidence of $\mathrm{CAH}$ in South Korea. The risk for cardiovascular, metabolic, skeletal, and psychiatric disorders was higher in $\mathrm{CAH}$ patients than in the general population. Given the higher adverse health outcomes and mortality risk, lifelong surveillance and an ideal treatment approach to improve long-term outcomes are warranted for $\mathrm{CAH}$ patients.

\section{CONFLICTS OF INTEREST}

No potential conflict of interest relevant to this article was reported.

\section{ACKNOWLEDGMENTS}

This study was funded by the Korea Health Technology R\&D Project through the Korea Health Industry Development Institute funded by the Ministry of Health \& Welfare, Republic of Korea (HI19C0189). We would like to thank the Committee of Rare Endocrine Disease of the Korean Endocrine Society. This study was supported by the National Health Insurance Service 
(NHIS-2020-1-478). The funders had no role in study design, data collection, data analysis, and writing the manuscript.

\section{AUTHOR CONTRIBUTIONS}

Conception or design: J.H.K., S.G.K. Acquisition, analysis, or interpretation of data: J.H.K., S.C., Y.A.L., J.L., S.G.K. Drafting the work or revising: J.H.K., S.C., Y.A.L., J.L., S.G.K. Final approval of the manuscript: J.H.K., S.C., Y.A.L., J.L., S.G.K.

\section{ORCID}

Jung Hee Kim https://orcid.org/0000-0003-1932-0234

Sin Gon Kim https://orcid.org/0000-0002-7430-3675

\section{REFERENCES}

1. Speiser PW, Arlt W, Auchus RJ, Baskin LS, Conway GS, Merke DP, et al. Congenital adrenal hyperplasia due to steroid 21-hydroxylase deficiency: an Endocrine Society Clinical Practice Guideline. J Clin Endocrinol Metab 2018;103: 4043-88.

2. Merke DP, Auchus RJ. Congenital adrenal hyperplasia due to 21-hydroxylase deficiency. N Engl J Med 2020;383: 1248-61.

3. Morikawa S, Nakamura A, Fujikura K, Fukushi M, Hotsubo T, Miyata J, et al. Results from 28 years of newborn screening for congenital adrenal hyperplasia in sapporo. Clin Pediatr Endocrinol 2014;23:35-43.

4. Tsuji A, Konishi K, Hasegawa S, Anazawa A, Onishi T, Ono $\mathrm{M}$, et al. Newborn screening for congenital adrenal hyperplasia in Tokyo, Japan from 1989 to 2013: a retrospective population-based study. BMC Pediatr 2015;15:209.

5. Li Z, Huang L, Du C, Zhang C, Zhang M, Liang Y, et al. Analysis of the screening results for congenital adrenal hyperplasia involving 7.85 million newborns in China: a systematic review and meta-analysis. Front Endocrinol (Lausanne) 2021;12:624507.

6. Arlt W, Willis DS, Wild SH, Krone N, Doherty EJ, Hahner S, et al. Health status of adults with congenital adrenal hyperplasia: a cohort study of 203 patients. J Clin Endocrinol Metab 2010;95:5110-21.

7. Finkielstain GP, Kim MS, Sinaii N, Nishitani M, Van Ryzin C, Hill SC, et al. Clinical characteristics of a cohort of 244 patients with congenital adrenal hyperplasia. J Clin Endocrinol Metab 2012;97:4429-38.
8. Krone N, Rose IT, Willis DS, Hodson J, Wild SH, Doherty EJ, et al. Genotype-phenotype correlation in 153 adult patients with congenital adrenal hyperplasia due to 21-hydroxylase deficiency: analysis of the United Kingdom Congenital adrenal Hyperplasia Adult Study Executive (CaHASE) cohort. J Clin Endocrinol Metab 2013;98:E346-54.

9. Han TS, Conway GS, Willis DS, Krone N, Rees DA, Stimson RH, et al. Relationship between final height and health outcomes in adults with congenital adrenal hyperplasia: United Kingdom congenital adrenal hyperplasia adult study executive (CaHASE). J Clin Endocrinol Metab 2014;99: E1547-55.

10. Falhammar H, Frisen L, Hirschberg AL, Norrby C, Almqvist $\mathrm{C}$, Nordenskjold A, et al. Increased cardiovascular and metabolic morbidity in patients with 21-hydroxylase deficiency: a Swedish population-based national cohort study. J Clin Endocrinol Metab 2015;100:3520-8.

11. Bonfig W, Roehl FW, Riedl S, Dorr HG, Bettendorf M, Bramswig J, et al. Blood pressure in a large cohort of children and adolescents with classic adrenal hyperplasia (CAH) due to 21-hydroxylase deficiency. Am J Hypertens 2016;29: 266-72.

12. Tamhane S, Rodriguez-Gutierrez R, Iqbal AM, Prokop LJ, Bancos I, Speiser PW, et al. Cardiovascular and metabolic outcomes in congenital adrenal hyperplasia: a systematic review and meta-analysis. J Clin Endocrinol Metab 2018;103: 4097-103.

13. Falhammar H, Frisen L, Norrby C, Hirschberg AL, Almqvist C, Nordenskjold A, et al. Increased mortality in patients with congenital adrenal hyperplasia due to 21-hydroxylase deficiency. J Clin Endocrinol Metab 2014;99:E2715-21.

14. Zhong K, Wang W, He F, Wang Z. The status of neonatal screening in China, 2013. J Med Screen 2016;23:59-61.

15. Gidlof S, Falhammar H, Thilen A, von Dobeln U, Ritzen M, Wedell A, et al. One hundred years of congenital adrenal hyperplasia in Sweden: a retrospective, population-based cohort study. Lancet Diabetes Endocrinol 2013;1:35-42.

16. Whittle E, Falhammar H. Glucocorticoid regimens in the treatment of congenital adrenal hyperplasia: a systematic review and meta-analysis. J Endocr Soc 2019;3:1227-45.

17. Bachelot A, Grouthier V, Courtillot C, Dulon J, Touraine P. Management of endocrine disease: congenital adrenal hyperplasia due to 21-hydroxylase deficiency: update on the management of adult patients and prenatal treatment. Eur J Endocrinol 2017;176:R167-81.

18. Han TS, Krone N, Willis DS, Conway GS, Hahner S, Rees 
DA, et al. Quality of life in adults with congenital adrenal hyperplasia relates to glucocorticoid treatment, adiposity and insulin resistance: United Kingdom Congenital adrenal Hyperplasia Adult Study Executive (CaHASE). Eur J Endocrinol 2013;168:887-93.

19. Bouvattier C, Esterle L, Renoult-Pierre P, de la Perriere AB, Illouz F, Kerlan V, et al. Clinical outcome, hormonal status, gonadotrope axis, and testicular function in 219 adult men born with classic 21-hydroxylase deficiency: a French national survey. J Clin Endocrinol Metab 2015;100:2303-13.

20. Torky A, Sinaii N, Jha S, Desai J, El-Maouche D, Mallappa A, et al. Cardiovascular disease risk factors and metabolic morbidity in a longitudinal study of congenital adrenal hyperplasia. J Clin Endocrinol Metab 2021;106:e5247-57.

21. Bachelot A, Golmard JL, Dulon J, Dahmoune N, Leban M, Bouvattier $\mathrm{C}$, et al. Determining clinical and biological indicators for health outcomes in adult patients with childhood onset of congenital adrenal hyperplasia. Eur J Endocrinol 2015;173:175-84.

22. Hu J, Zhang Z, Shen WJ, Azhar S. Cellular cholesterol delivery, intracellular processing and utilization for biosynthesis of steroid hormones. Nutr Metab (Lond) 2010;7:47.

23. Diamanti-Kandarakis E, Dunaif A. Insulin resistance and the polycystic ovary syndrome revisited: an update on mechanisms and implications. Endocr Rev 2012;33:981-1030.

24. Paizoni L, Auer MK, Schmidt H, Hubner A, Bidlingmaier M, Reisch N. Effect of androgen excess and glucocorticoid exposure on metabolic risk profiles in patients with congenital adrenal hyperplasia due to 21-hydroxylase deficiency. J Steroid Biochem Mol Biol 2020;197:105540.

25. Lim SG, Lee YA, Jang HN, Kong SH, Ahn CH, Kim SW, et al. Long-term health outcomes of korean adults with classic congenital adrenal hyperplasia due to 21-hydroxylase defi- ciency. Front Endocrinol (Lausanne) 2021;12:761258.

26. Deitelzweig SB, Lin J, Johnson BH, Schulman KL. Venous thromboembolism in the US: does race matter? J Thromb Thrombolysis 2011;31:133-8.

27. Falhammar H, Filipsson H, Holmdahl G, Janson PO, Nordenskjold A, Hagenfeldt K, et al. Fractures and bone mineral density in adult women with 21-hydroxylase deficiency. J Clin Endocrinol Metab 2007;92:4643-9.

28. Riehl G, Reisch N, Roehle R, Claahsen van der Grinten H, Falhammar H, Quinkler M. Bone mineral density and fractures in congenital adrenal hyperplasia: findings from the dsd-LIFE study. Clin Endocrinol (Oxf) 2020;92:284-94.

29. Auer MK, Paizoni L, Hofbauer LC, Rauner M, Chen Y, Schmidt H, et al. Effects of androgen excess and glucocorticoid exposure on bone health in adult patients with 21-hydroxylase deficiency. J Steroid Biochem Mol Biol 2020;204: 105734.

30. Falhammar H, Butwicka A, Landen M, Lichtenstein P, Nordenskjold A, Nordenstrom A, et al. Increased psychiatric morbidity in men with congenital adrenal hyperplasia due to 21-hydroxylase deficiency. J Clin Endocrinol Metab 2014; 99:E554-60.

31. Engberg H, Butwicka A, Nordenstrom A, Hirschberg AL, Falhammar H, Lichtenstein $\mathrm{P}$, et al. Congenital adrenal hyperplasia and risk for psychiatric disorders in girls and women born between 1915 and 2010: a total population study. Psychoneuroendocrinology 2015;60:195-205.

32. Jenkins-Jones S, Parviainen L, Porter J, Withe M, Whitaker MJ, Holden SE, et al. Poor compliance and increased mortality, depression and healthcare costs in patients with congenital adrenal hyperplasia. Eur J Endocrinol 2018;178:30920 . 